\title{
A New Physiologic Based Integrated Algorithm in the Management of Neonatal Hemodynamic Instability
}

Yasser Elsayed ( $\square$ yassernabawy97@gmail.com )

$U$ of Manitoba

Muzafar Abdul Wahab

McMaster University

\section{Research Article}

Keywords: Integrated hemodynamics, neonatal hemodynamic instability, circulatory shock

Posted Date: March 16th, 2021

DOI: https://doi.org/10.21203/rs.3.rs-285959/v1

License: (a) (1) This work is licensed under a Creative Commons Attribution 4.0 International License.

Read Full License

Version of Record: A version of this preprint was published at European Journal of Pediatrics on November 8th, 2021. See the published version at https://doi.org/10.1007/s00431-021-04307-5. 


\section{Abstract}

Physiologic based management of hemodynamic instability is proven to guide to logical selection of cardiovascular approach, and shorten time to clinical recovery, compared to empiric approach which is ignoring the heterogeneity of the hemodynamic instability related mechanisms. In this report we classified neonatal hemodynamic instability, circulatory shock, and degree of compensation to 5 physiologic categories, based on blood pressure (BP) different phenotypes, other clinical parameters, echocardiography markers, and oxygen indices. This approach is focused on hemodynamic instability in infants with normal heart structure.

\section{Summary}

What is known?

Physiologic assessment of hemodynamics leads to targeted and pathophysiologic based medical recommendation.

What is new?

Hemodynamic instability in neonates can be categorized according to the underlaying mechanism to five main categories, based on blood pressure phenotypes, systemic vascular resistance, and myocardial performance.

\section{Background}

The new classification helps to targeted management, and logical selection of cardiovascular support.

Stepwise compensatory mechanisms from stability to decompensation:

The stable state is a complex process of interaction between diverse body humoral regulators, baroreceptors, and chemoreceptors, and they are all under a balanced control of the autonomic nervous system; all vital functions during the stable state are marinated within an acceptable range within which cellular needs of oxygen and nutrition are maintained.

During any temporary period of instability, the first and fast compensatory mechanism that takes place, within a fraction of seconds, is autoregulation, and it happens with any fluctuations or changes of the parameters affecting oxygen delivery, for example; fluctuation of oxygen saturation, carbon dioxide, blood flow or blood pressure. Autoregulation is typically a local release of nitric oxide, by red blood cells, with subsequent local vasodilatation of blood vessels, at any specific area of reduced oxygen delivery or when demand exceeds delivery. If the oxygen delivery is less than the demand at any time beyond the capacity of autoregulation, then tissue extracts more oxygen than usual to maintain aerobic metabolism; this can be detected in real-time on near infrared spectroscopy (NIRS) as low regional tissue oxygen saturation (StO2) and increased the calculated oxygen extraction, assessment of both trends and histograms are 
helpful for early detection of the decompensation. Anaerobic metabolism is the last mechanism to compensate if decreased oxygen delivery is lower than the maximum capacity of the tissue to extract the oxygen required to maintain aerobic metabolism; figure 1 demonstrates the impact of different mechanisms of hypoxia on oxygen delivery (D02), oxygen consumption (V02), and fractional oxygen extraction (FOE)(1).

Physiology of blood pressure components:

Diastolic blood pressure (DBP) is the baseline arterial pressure maintained by the vascular tone of the arterioles under many neuronal and humoral vasopressors, which are responsible for maintaining systemic vascular resistance (SVR) (1). Ejection of stroke volume creates an increase of pressure from the baseline diastolic to the peak systolic; this is the pulse pressure, so the two relatively independent blood pressure components are the diastolic pressure and pulse pressure, both make two other dependant components, the systolic pressure (SBP) which is the sum of both values, and both in different ratio make the mean blood pressure (MABP) which can be calculated in many different ways, e.g. (2/3 $\mathrm{DBP}+1 / 3 \mathrm{SBP})$, figure 1 demonstrates the blood pressure changes in different mechanisms of shock(1).

Critical parameters for assessment of hemodynamics, oxygen delivery and consumption:

1- Left ventricular output (LVO), expressed as $\mathrm{ml} / \mathrm{kg} / \mathrm{min}$ :

The velocity-time integral (VTI) of aortic flow is measured using pulse-wave Doppler from an apical fivechamber view by placing the sampling gate at the level of the hinge point of the aortic valve. Trans-aortic root diameter is measured at the hinge points of the valve from the parasternal long-axis view in the 2D image. LVO can be then calculated as (Ao CSA x VTI x heart rate) / weight in kg, where Ao CSA= crosssectional area of the aortic valve.

2- Systemic vascular resistance expressed as $\mathrm{mmHg} \mathrm{l} / \mathrm{L} / \mathrm{kg} / \mathrm{min}$ :

It can be calculated by dividing the LVO by mean blood pressure (MABP); the normal SVR in the stable preterm infant has been published as the mean of 192 (149-246) $\mathrm{mmHg} \mathrm{l/} \mathrm{L/} \mathrm{kg/} \min (1)$.

3- Monitoring of tissue oxygenation:

Arterial Oxygen saturation (Sp02) can be monitored by a pulse oximeter and tissue oxygen saturation StO2 by near-infrared spectroscopy. Fractional oxygen extraction FOE calculated as the ratio between SpO2 and StO2(1).

Calculation of oxygen delivery (D02):

$\mathrm{DO} 2=\mathrm{LVO} \times$ oxygen content $=\mathrm{LVO}(\mathrm{ml} \mathrm{kg} / \mathrm{min}) \times 1.39 \times \mathrm{Hb}(\mathrm{g} / \mathrm{ml}) \times \mathrm{SpO} 2$ (expressed as a fraction)

Right ventricle output should be used in cases of a hemodynamically significant patent ductus arteriosus (HSPDA) for a more accurate representation of systemic blood flow as LVO, in this case, is more 
representative of the pulmonary over-circulation(4).

FOE calculated as $=(\mathrm{SpO} 2-\mathrm{StO} 2) / \mathrm{SpO} 2$ (all expressed as fractions $)$

Oxygen consumption (VO2) calculated as:

Since FOE $=$ VO2 $/ \mathrm{DO} 2$, Then organ-specific VO2 $(\mathrm{ml}$ of oxygen $\mathrm{kg} / \mathrm{min})=$ systemic $\mathrm{DO} 2 \times$ organ-specific FOE(1).

Figure 2 demonstrated the impact of different mechanisms of shock on oxygen delivery, consumption and extraction.

4- Other clinical parameters:

Other clinical parameters are important but limited if interpreted in isolation from other hemodynamic components, including urine output (UOP), metabolic acidosis, perfusion index, heart rate variability, and non-invasive continuous monitoring of blood flow(5).

Categorized evaluation and management of hemodynamic instability:

Category I Hemodynamic instability due to Vasodilator physiology:

Many diseases and factors may decrease SVR and cause vasodilator circulatory shock. This is the most common cause of shock in the neonatal age group, and it could be related to neonatal septicemia or systemic inflammatory response syndrome to circulating cytokines. Vasodilatory physiology might be associated with hypoxemia secondary to hypoxemic respiratory failure, pulmonary hypertension, or congenital heart diseases(6). It is also reported in late-onset compromised systemic circulation in preterm infants, hypoxic-ischemic encephalopathy, metabolic acidosis with low $\mathrm{PH}$. Vasodilator physiology could be iatrogenic secondary vasodilator medications, e.g., anesthesia, milrinone, Dobutamine, and opioids(8).

The DBP decreases below the acceptable average level or trending down over time as shown on the monitor or as represented on histograms, pulse pressure stays normal, SBP decreases secondary to decrease in DBP, MABP also decreases secondary to decrease in $\mathrm{DBP}(10)$.

The systolic cardiac functions are normal or hyperdynamic, and the calculated SVR is low, and oliguria or decrease in urine output $<1 \mathrm{ml} / \mathrm{kg} /$ hour for at least 12 hours beyond the first 12 hours after birth. An increase in end-organ oxygen extraction measured by NIRS is a sign of compromised oxygen delivery, and if increased extraction reached the maximum capacity, then lactic acidosis is a late sign before progression to end-organ dysfunction(10).

Management should be directed to treat the underlying etiology and an appropriate dose of vasopressor to maintain both vascular resistance and oxygen delivery. The figure shows the blood pressure trend for the infant with vasodilator physiology; figure 3 is a case scenario of vasodilator physiology(1). 
Category II, hemodynamics instability due to vasoconstrictor physiology:

This category is characterized as a state of high afterload with failure of myocardial systolic performance against SVR; it usually happens with a sudden increase of SVR or relatively immature myocardium(11). The most common causes in neonates are a premature infant with failure of postnatal circulatory adaptation, hypoxic-ischemic encephalopathy, post PDA ligation cardiovascular compromise, post-AVM embolization, and it can also be associated with pulmonary hypertension(3). The DBP is normal to high or trending higher than the baseline, the pulse pressure is narrow below the acceptable level, low SBP, and normal MABP, and this category is commonly missed if the neonatal team is relying solely on MABP for monitoring hemodynamic instability(3). The cardiac systolic performance is impaired, and the calculated SVR is high, and oliguria, lactic acidosis, and NIRS assessment are similar to category $\mathrm{I}(2)$.

Management should be directed to treat the underlying etiology together with an appropriate dose of vasodilator with an inotropic effect like Dobutamine or milrinone to maintain decrease both SVR and afterload; figure 4 is a case scenario of vasoconstrictor physiology.

Category III, cardiogenic shock:

This category is characterized as a state of circulatory failure due to impaired myocardial systolic performance with low SVR. The most common causes in neonates are premature infants with failure of postnatal circulatory adaptation, hypoxic-ischemic encephalopathy, cardiac arrhythmias, myocarditis; it can also happen with a high dose of inotropes due to impaired diastolic filling of the heart. All BP components are low, including narrow pulse pressure. The cardiac systolic performance is impaired, and the calculated SVR is low, oliguria, lactic acidosis, and NIRS assessment are similar to category I(1). Management should be directed to treat the underlying etiology and an appropriate dose of inotropic with a vasopressor effect like Epinephrine or Dopamine, figure 5 is a case scenario of cardiogenic shock.

Category IV, shunt physiology:

It is a state of decreased blood flow in diastole due to blood shunts through PDA, mainly in preterm infants. It is characterized by low DBP, wide pulse pressure, low MABP, echocardiography in significant PDA shows left heart volume overload, with the absent or reversed diastolic flow by Doppler in post ductal aortic branches; figure 3 demonstrates the different phenotypes of blood pressure changes in different categories of hemodynamic instability(1).

Category V: volume depletion:

Depletion of intravascular volume due to excessive losses either outside the body e.g., high urine output; or gastrointestinal losses, or third space losses secondary to capillary leak syndrome which could be due to infection or systemic inflammatory process. Venous return could be depleted in severe pulmonary hypertension or high mean airway pressure. Restricted heart filling with low cardiac output could be secondary to myocardial hypertrophy either idiopathic or in infant of diabetic mothers. Management 
should be directed to treat the underlaying cause and fluid resuscitation until the intravascular volume restored, inotropic support should be avoided in this category, table 1 demonstrates the changes in different hemodynamic parameters in the five categories of hemodynamic instability.

Challenges of hemodynamic management: some case scenarios might have multiple underlying pathophysiologic mechanisms, for instance, a preterm infant with vasodilator physiology and significant shunt at the same time, or an infant with pulmonary hypertension and low systemic blood flow due to left ventricular dysfunction, in these challenging conditions it is essential to prioritize the lines of treatment, and it is better to directed by an expert in neonatal hemodynamics, figure 6 is a comprehensive algorithm to guide management of neonatal hemodynamics instability $(1,3)$.

The future directions:

The researchers are currently working on understanding autoregulation, earlier prediction of shock, data acquisition to develop innovative machine learning that can give predictive clinical scores which can be accessed by the clinical team in real-time and react accordingly. The availability of clinical decision support systems supports clinicians during critical decision-making with a physiologic direction to management.

\section{Conclusion}

The management of hemodynamic instability is challenging due to the complexity of the pathophysiology; integrating different monitoring techniques is essential to understand the undelaying pathophysiologic mechanism and formulate a physiologic based medical recommendation, more research is still needed to validate the physiologic approach.

\section{Abbreviations}

BP: Blood pressure

DBP: Diastolic blood pressure

D02: Oxygen delivery

FOE: Fractional oxygen extraction

PDA: Patent ductus arteriosus

MABP: Mean arterial blood pressure

NIRS: near infrared spectroscopy

St02: Tissue oxygen saturation 
VO2: Oxygen consumption

SBP: Systolic blood pressure

Sp02: Arterial oxygen saturation

SVR: systemic vascular resistance

\section{Declarations}

Compliance with ethical standards: N/A

Consent to participate: N/A

Consent for publication: Yes

Availability of data and material: Yes

Conflict of interest: the authors declare that they have no conflict of interest.

Funding: No funding was received

Ethical approval: This article does not contain any studies with human participants or animals performed by any of the authors.

Code availability: N/A

Author contributions: YE and MA conceptualized the article. YE and MA conducted the background literature search. YE devised the manuscript and both authors agree to the formatting and contents.

\section{References}

1. Elsayed YN, Louis D, Ali YH, Amer R, Seshia MM, Patrick •, et al. Integrated evaluation of hemodynamics: a novel approach for the assessment and management of preterm infants with compromised systemic circulation. J Perinatol. 2018;(1).

2. Giesinger RE, Elsayed YN, Castaldo MP, McNamara PJ. Targeted Neonatal Echocardiography-Guided Therapy in Vein of Galen Aneurysmal Malformation: A Report of Two Cases with a Review of Physiology and Approach to Management. AJP Rep. 2019;9(2):E172-6.

3. Selim A, El Wahab AA, Salem H, Yahmadi M Al, Al Aisary S, Malviya M, et al. Perioperative management of arteriovenous malformation guided by integrated evaluation of hemodynamics. Eur J Pediatr. 2020;

4. Amer R, Elsayed YN, Graham MR, Sikarwar AS, Hinton M, Dakshinamurti S. Effect of vasopressin on a porcine model of persistent pulmonary hypertension of the newborn. 2019;(December 2018):31932. 
5. Limperopoulos C, Gauvreau KK, O'Leary H, Moore M, Bassan H, Eichenwald EC, et al. Cerebral Hemodynamic Changes During Intensive Care of Preterm Infants. Pediatrics [Internet]. 2008;122(5):e1006-13. Available from: http://pediatrics.aappublications.org/content/122/5/e1006\%5Cnhttp://files/413/Limperopoulos et al. - 2008 - Cerebral Hemodynamic Changes During Intensive Care.pdf\%5Cnhttp://www.ncbi.nIm.nih.gov/pubmed/18931348\%5Cnhttp://files/414/e1006.html

6. Elsayed Y FD. Integrated Evaluation of Neonatal Hemodynamics, Part 2: Systematic Bedside Assessment. 2016;192-203.

7. Chock VY, Ramamoorthy C, Van Meurs KP. Cerebral Autoregulation in Neonates with a Hemodynamically Significant Patent Ductus Arteriosus. J Pediatr [Internet]. 2012 Jan [cited 2012 May 5];160(6):936-42. Available from: http://linkinghub.elsevier.com/retrieve/pii/S0022347611012285

8. Dempsey E, Cabañas F, De Boode WP, Vrancken SL, Van Heijst AF. Neonatal Hemodynamics: From Developmental Physiology to Comprehensive Monitoring. Front Pediatr. 2018;687(6):1-15.

9. Parker MM. Hemodynamics in Preterm Neonates With Septic Shock. Pediatr Crit Care Med [Internet]. 2014;15:494-5. Available from: http://content.wkhealth.com/linkback/openurl? sid=WKPTLP:landingpage \&an $=00130478-201406000-00015$

10. Amer R, Kalash R, Seshia MM, Elsayed YN. The Impact of Integrated Evaluation of Hemodynamics on Management of Preterm Infants with Late-Onset Compromised Systemic Circulation. Am J Perinatol. 2017;

11. Elsayed Y, Fraser D. Integrated Evaluation of Neonatal Hemodynamics Program Optimizing Organ Perfusion and Performance in Critically III Neonates, Part 1 : Understanding Physiology of Neonatal Hemodynamics. 2016;143-50.

\section{Table}


Table 1:

comparison between different types of circulatory shock, StO2: tissue oxygen saturation by NIRS, FOE: fractional oxygen extraction, COP: cardiac output, SVR: systemic vascular resistance, DO2: oxygen delivery. $(-)$ : decreased trend, $( \pm)$ : no significant change, $(+)$ : increased trend, $(-/+)$ may decrease or increase.

\begin{tabular}{|c|c|c|c|c|c|}
\hline & $\begin{array}{l}\text { Vasodilator } \\
\text { physiology }\end{array}$ & $\begin{array}{l}\text { Cardiogenic } \\
\text { shock }\end{array}$ & $\begin{array}{l}\text { Vasoconstrictor } \\
\text { physiology }\end{array}$ & $\begin{array}{l}\text { Shunt } \\
\text { physiology }\end{array}$ & $\begin{array}{l}\text { Volume } \\
\text { Depletion }\end{array}$ \\
\hline \multicolumn{6}{|c|}{ Blood pressure components } \\
\hline Diastolic BP & -- & -- & + & - & \pm \\
\hline $\begin{array}{l}\text { Pulse } \\
\text { pressure }\end{array}$ & \pm & -- & -- & + & - \\
\hline Systolic BP & - & -- & - & \pm & - \\
\hline Mean BP & -- & -- & \pm & \pm & \pm \\
\hline \multicolumn{6}{|c|}{ Perfusion and end organ indices } \\
\hline $\begin{array}{l}\text { Perfusion } \\
\text { index }\end{array}$ & + & - & \pm & + & \pm \\
\hline $\begin{array}{l}\text { Capillary } \\
\text { refill time }\end{array}$ & + & - & \pm & + & \pm \\
\hline Urine output & \pm & \pm & \pm & \pm & - \\
\hline $\begin{array}{l}\text { Metabolic } \\
\text { acidosis }\end{array}$ & \pm & \pm & \pm & \pm & \pm \\
\hline $\begin{array}{l}\text { Lactic } \\
\text { acidosis }\end{array}$ & \pm & \pm & \pm & \pm & \pm \\
\hline StO2 & $-/+$ & $-/+$ & $-/+$ & $-/+$ & $-/+$ \\
\hline \multicolumn{6}{|l|}{ Echo indices } \\
\hline $\begin{array}{l}\text { Shortening } \\
\text { fraction }\end{array}$ & \pm & - & - & + & \pm \\
\hline $\begin{array}{l}\text { Ejection } \\
\text { fraction }\end{array}$ & \pm & - & - & + & \pm \\
\hline $\begin{array}{l}\text { End systolic } \\
\text { volume }\end{array}$ & \pm & \pm & \pm & + & - \\
\hline \multicolumn{6}{|c|}{ Calculated indices } \\
\hline $\begin{array}{l}\text { Calculated } \\
\text { FOE }\end{array}$ & $-/+$ & $-/+$ & $-/+$ & $-/+$ & $-/+$ \\
\hline $\begin{array}{l}\text { Calculated } \\
\text { COP }\end{array}$ & \pm & -- & - & - & - \\
\hline Calculated & -- & - & + & + & \pm \\
\hline
\end{tabular}




$\pm \quad-$

\section{Figures}

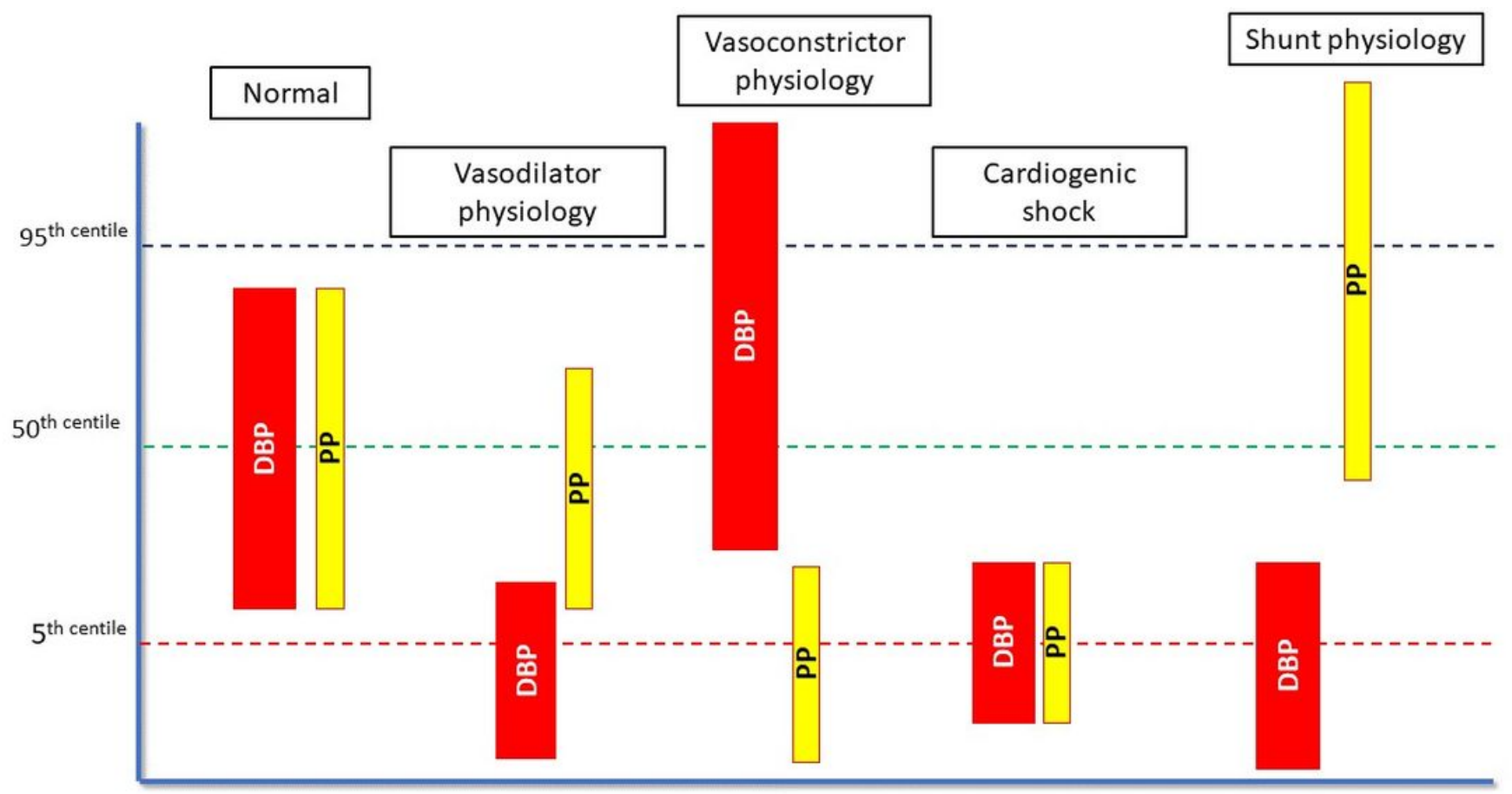

\section{Figure 1}

The 4 main categories of hemodynamic instability in neonates as per the 2 independent blood pressure components, Diastolic blood pressure (DBP), and pulse pressure (PP), in normal blood pressure both DBP and PP are maintained between the 5th and 95th centile for any given gestational age, vasodilator physiology DBP is trending down but PP is maintained. Vasoconstrictor physiology the DBP is trending up with PP is narrow, in cardiogenic shock both DBP and PP are low, in shunt physiology DBP is low but $\mathrm{PP}$ is wide. 


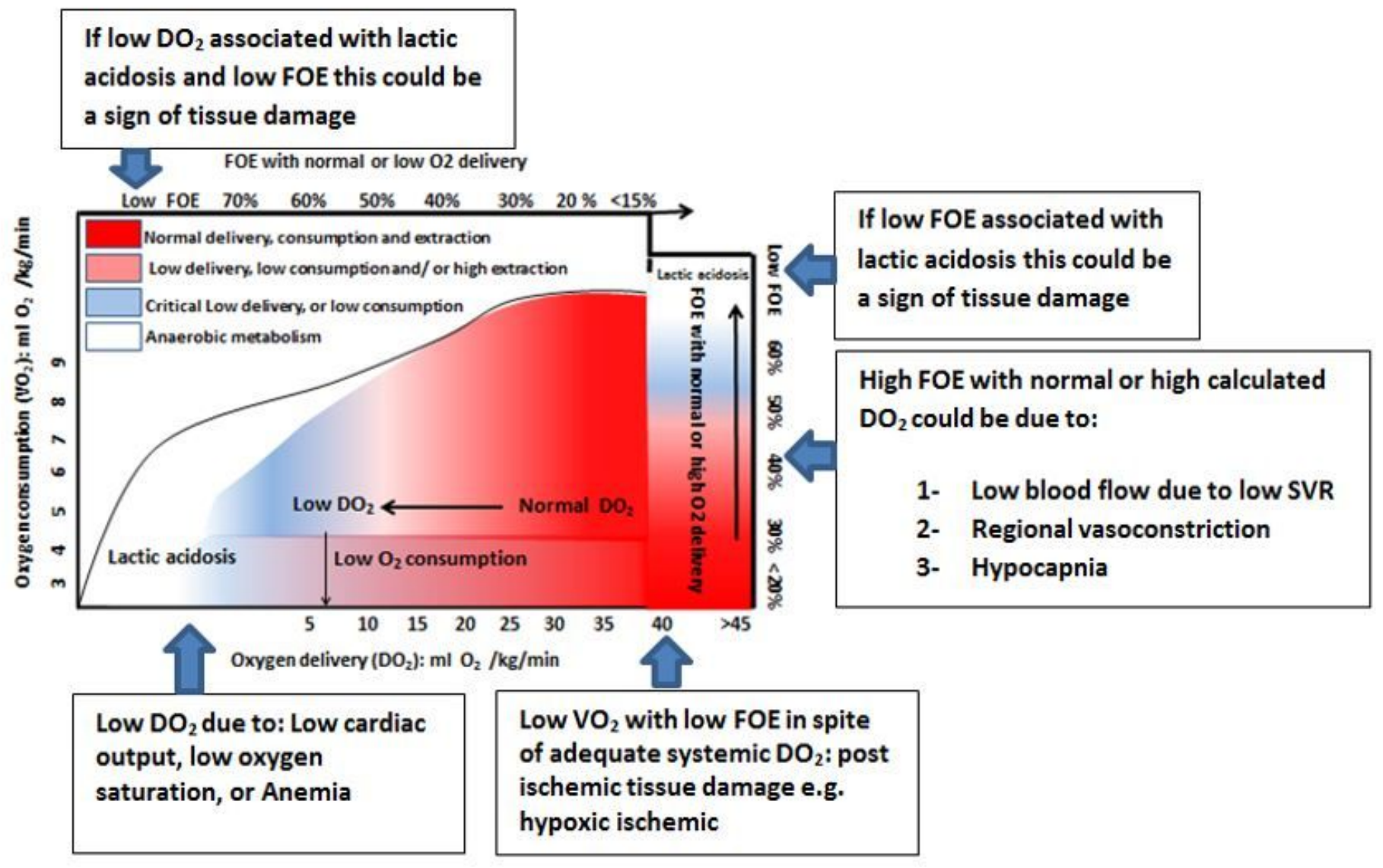

Figure 2

This multidimensional graph is simplifying the 3 main mechanisms of hypoxia in neonates (1-3), and the decompensated stage with anaerobic metabolism (4). The 3 calculated oxygen indices are oxygen delivery (D02), oxygen consumption (VO2) and fractional oxygen extraction (FOE): the lower $x$ axis is representing the trend of D02, left side direction means decreasing DO2 (lower $\mathrm{X}$ axis), the left $\mathrm{Y}$ axis is representing the $\mathrm{VO} 2$ and downward direction is decreasing $\mathrm{VO} 2$, the right $\mathrm{Y}$ axis and upper $\mathrm{X}$ axis is representing the FOE as percent. Mechanism 1: Low capacity of tissue to extract oxygen due to prolonged hypoxemic ischemic injury, although DO2 is adequate but both VO2 and FOE are low. Mechanism 2: Low oxygen delivery due to severe anemia, hypoxemia, or low cardiac output, represented as low D02 and subsequently low VO2 and high FOE to compensate for low DO2. Mechanism 3: Although calculated DO2 is normal or high and cardiac output is normal or high, the FOE is high due to low SVR which is not included in D02 equation, or regional vasoconstriction and hypocapnia is one of the common causes of cerebral vasocontraction which can be detected on NIRS as high FOE. Mechanism 4: if situation 2 or 3 continued and the DO2 is insufficient to maintain aerobic metabolism then anaerobic metabolism with lactic acidosis takes place to maintain energy production, but at the same time FOE decreases to low levels due to exhaustion of aerobic metabolism. 


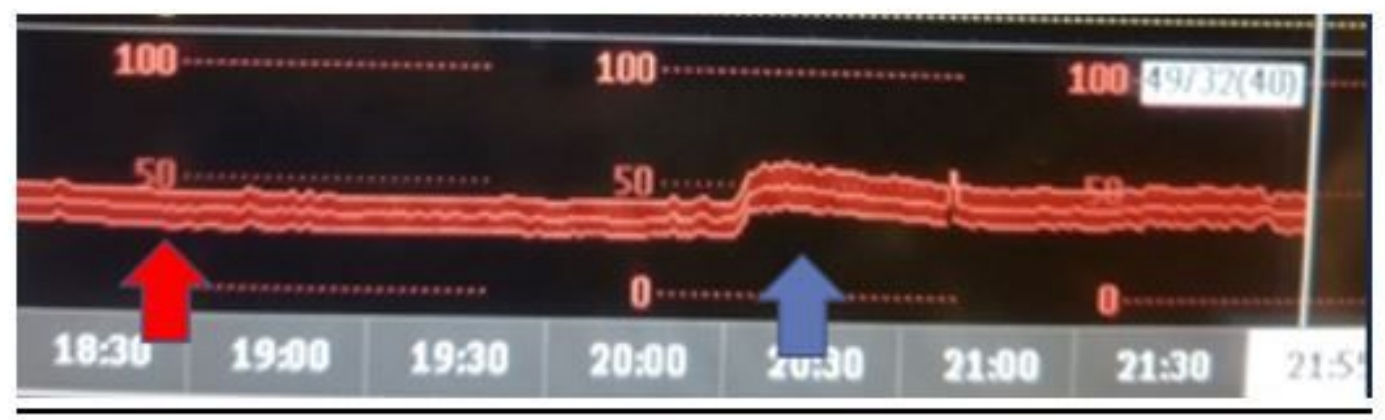

\section{Figure 3}

Preterm infant PMA 32 weeks with lactic acid of $5 \mathrm{mmol} / \mathrm{l}$, the 3 parallel red lines representing SBP, MABP, and DBP, the red area is the pulse pressure (PP), both DBP and SBP are trending down but with maintained PP starting at 18:30 (red arrow) to $20: 00$ at rate of $5 \mathrm{mmHg} / \mathrm{hr}$ continues drop consistent with vasodilator physiology (category I). Vasopressor was started at 20:15 with improvement of the $3 \mathrm{BP}$ components.

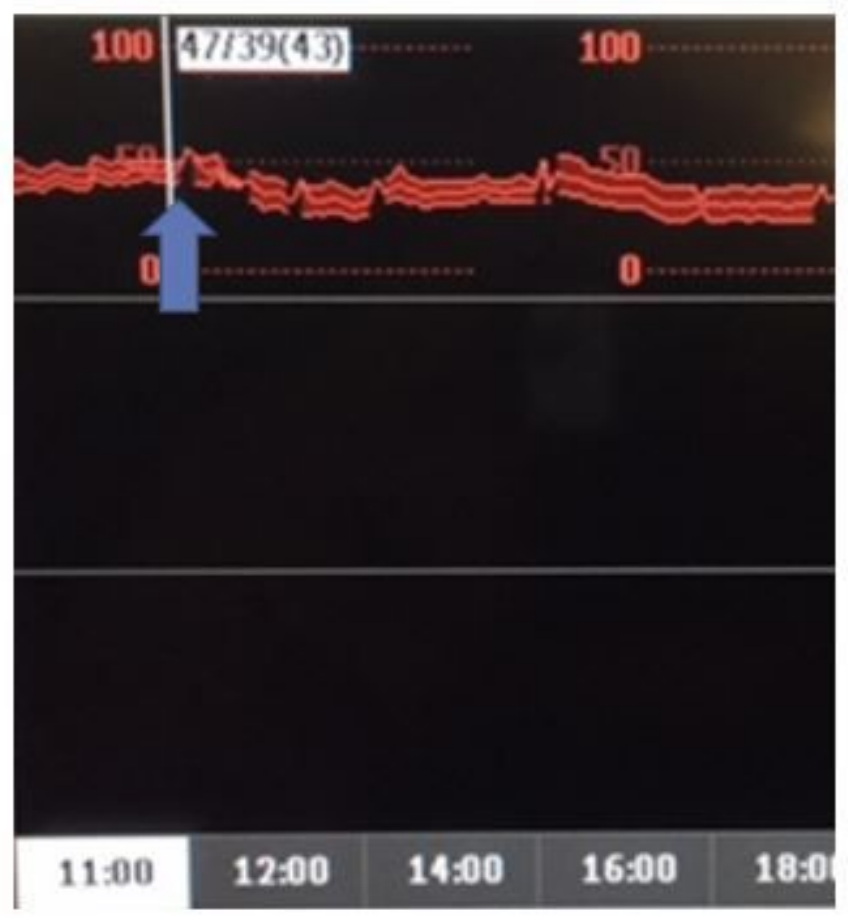

\section{Figure 4}

Preterm 31 weeks 7 days of life, DBP increased with drop of PP to $7 \mathrm{mmHg}$ (consistent with vasoconstrictor physiology) associated with lactic acid of $6 \mathrm{mmol} / \mathrm{l}$. Improvement with widening of PP can be noticed after start of vasodilator with inotropic effect. 


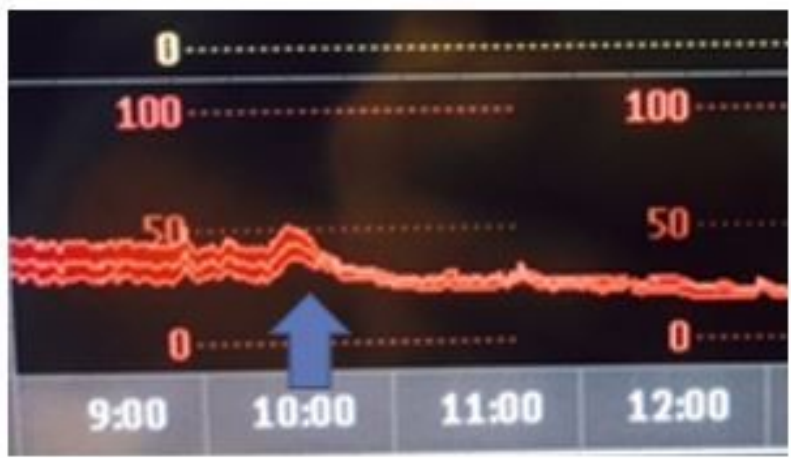

\section{Figure 5}

Preterm infant 25 weeks first day of life, DBP and SPB decreased at 10 am with narrow of PP (blue arrow), 5 hours later without treatment lactic acid increased to $5 \mathrm{mmol} / \mathrm{l}$, this infant improved shortly after start of inotropic support.

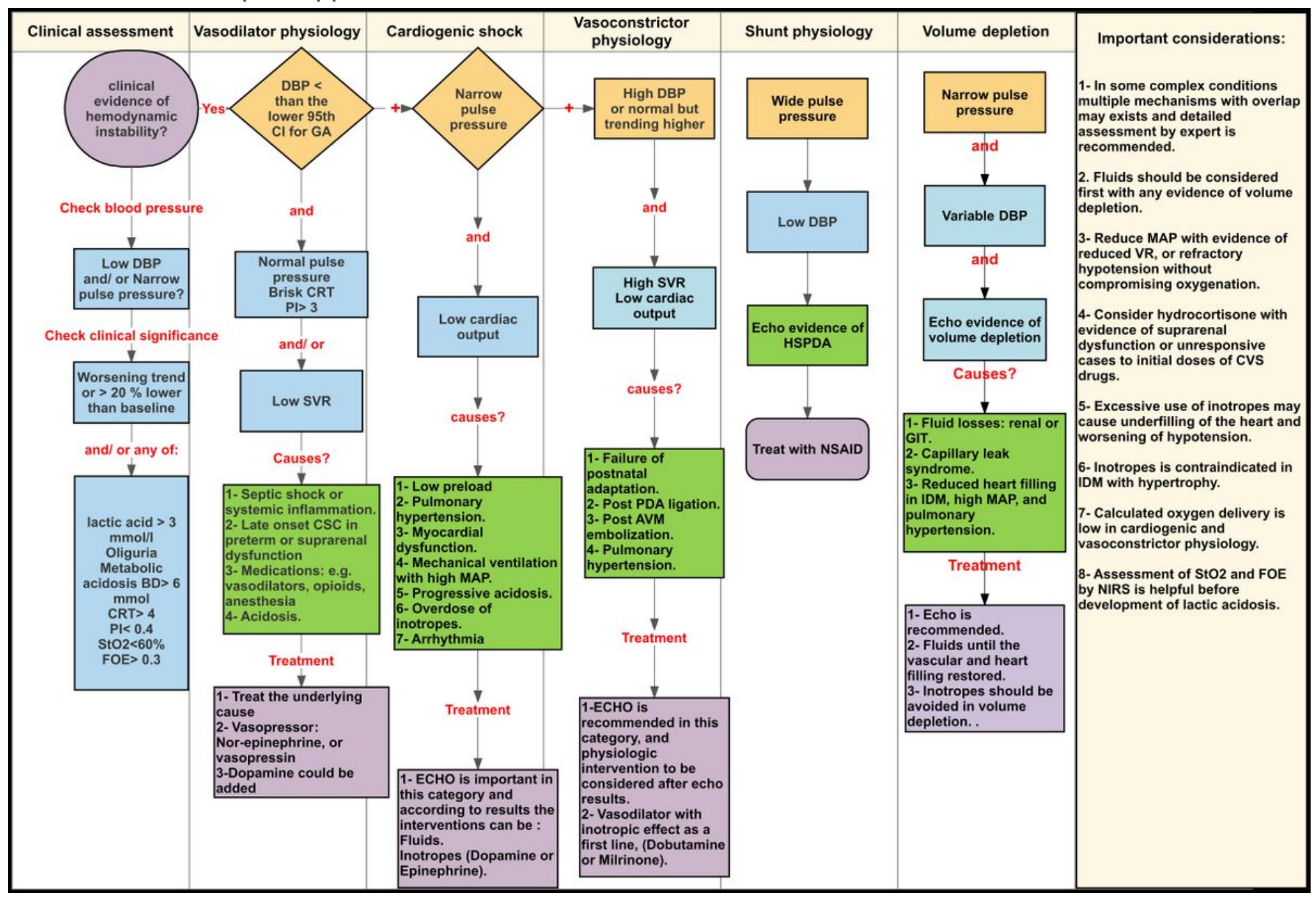

\section{Figure 6}

Algorithm to guide integrated physiologic management of neonatal hemodynamic instability, CRT: capillary refile time, PI: perfusion index, StO2: tissue oxygen saturation, HSPDA: hemodynamically 
significant PDA, NSAID: non steroidal anti-inflammatory drug. + sign means add of the 2 features before and after the sign.

\section{Supplementary Files}

This is a list of supplementary files associated with this preprint. Click to download.

- BPTABLES.doc 